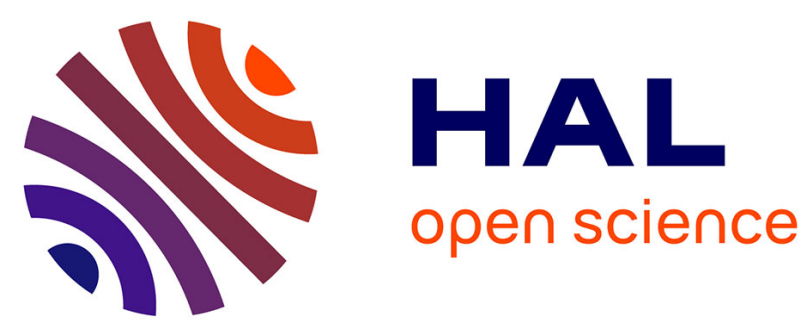

\title{
PLGA with less than 1 month of half-life time: Tensile properties in dry and wet states and hydrolytic degradation
}

Charlotte Duval, Rachid Rahouadj, Cécile Nouvel, Jean-Luc Six

\section{- To cite this version:}

Charlotte Duval, Rachid Rahouadj, Cécile Nouvel, Jean-Luc Six. PLGA with less than 1 month of half-life time: Tensile properties in dry and wet states and hydrolytic degradation. International Journal of Polymeric Materials and Polymeric Biomaterials, 2017, 67 (8), pp.509-516. 10.1080/00914037.2017.1354197 . hal-02058225

\section{HAL Id: hal-02058225 \\ https://hal.univ-lorraine.fr/hal-02058225}

Submitted on 17 Mar 2021

HAL is a multi-disciplinary open access archive for the deposit and dissemination of scientific research documents, whether they are published or not. The documents may come from teaching and research institutions in France or abroad, or from public or private research centers.
L'archive ouverte pluridisciplinaire HAL, est destinée au dépôt et à la diffusion de documents scientifiques de niveau recherche, publiés ou non, émanant des établissements d'enseignement et de recherche français ou étrangers, des laboratoires publics ou privés. 
PLGA With Less Than One Month Half-Life Time: Tensile Properties In Dry And Wet States And Hydrolytic Degradation

Charlotte DUVAL ${ }^{\mathrm{a}, \mathrm{b}}$, Rachid RAHOUADJ ${ }^{\mathrm{c}}$, Cécile NOUVEL ${ }^{\mathrm{a}, \mathrm{b}}$, Jean-Luc SIX ${ }^{\mathrm{a}, \mathrm{b}}$ *

a) Université de Lorraine, Laboratoire de Chimie Physique Macromoléculaire LCPM, UMR 7375, Nancy F-54000, France

b) CNRS, Laboratoire de Chimie Physique Macromoléculaire LCPM, UMR 7375, Nancy F54000, France

c) Laboratoire d'Energétique et de Mécanique Théorique Appliquée, UMR 7563 CNRSLorraine University, ENSEM, 54504 Vandœuvre-lès-Nancy, France

corresponding author: Jean-Luc SIX (E-mail: jean-luc.six@univ-lorraine.fr) 


\begin{abstract}
.
In this study, the degradation mechanism and tensile properties of plasticized PLGA are evaluated. Purasorb® PDLG 5010 is first extruded into rods with or without plasticizers, i.e; D,L-lactide or aspirin. Then, the hydrolytic degradation of such rods is studied in PBS. A very fast hydrolytic degradation (half-life time lower than one month) that is enhanced by the presence of plasticizer occurs via a heterogeneous mechanism and leads to the formation of hollow rods. The mechanical properties of these rods are studied in dry and wet states. Finally, water diffusivity in plasticized (or not) PLGA are estimated.
\end{abstract}

Keywords: Biodegradable polymers; polyesters; mechanical properties; Weibull distribution 


\section{Introduction}

PLA (polylactide, polylactic acid), one of the most-known biobased polyester produced by fermentation of renewable agricultural resources, i.e. starch from corn, sugar beet or wheat, has the advantages to be biocompatible and bioabsorbable.[1-3] Besides PLA, some other biodegradable (co)polyesters such as poly( $\varepsilon$-caprolactone) (PCL), polyglycolide (PGA) or poly(D,L-lactide-co-glycolide) (PLGA) are also extensively used in pharmaceutical, biomedical and environmental fields.[4] For example, since 30 years ago, PLAs and PLGAs are widely employed in medical implantable devices such as sutures,[5] bone screws and plates,[6] or orthopedic implants.[7] Furthermore and in a very interesting way, these polymers are currently being tested to develop fully biodegradable stents as low half-life time coronary ones.[8,9]

PLGA can be synthesized by direct condensation of lactic and glycolic acids, or by the RingOpening coPolymerization (ROP) of cyclic lactide and glycolide dimers. While the polycondensation involves high temperature and pressure, it does not allow the synthesis of high molecular weight copolymers and removing water as by-product is unavoidable during all the process. $[10,11]$ Consequently, most of the works have been focused on the ROP due to a lot of benefits. The ROP takes place in milder reaction conditions, needs shorter reaction times, leads to high molecular weight polymers with narrow dispersity, and no by-products have to be removed. Tin(II) 2-ethylhexanoate (stannous octoate, $\mathrm{SnOct}_{2}$ ) is the most widely used catalyst to promote this ROP, but a lot of progress was recently accomplished through the development of both organocatalysts [12-14] or less toxic metallic catalysts such as Bismuth subsalicylate (BiSS),[15-17] for instance.

PLAs and PLGAs have good hydrolytic degradation and mechanical properties that depend on several parameters. Indeed, these polymers are degraded into lactic and glycolic acids, which are non-toxic for the mammalian bodies and are metabolized to water and carbon 
dioxide. For instance, the degradation rate of such polyesters can be modified by varying different parameters such as the (co)polymer composition, the molecular weight, the degree of crystallinity or the incorporation of additives.[18] While mechanical properties can be regulated through the lactic acid/glycolic acid ratio for instance, it also depends on tacticity: poly(L-lactide) (PLLA) and poly(D,L-lactide) (PDLLA) with the same molecular weight $\left(\overline{\mathrm{M}_{\mathrm{n}}}=100.000 \mathrm{~g} / \mathrm{mol}\right)$ exhibit high Young's modulus (2.7 and $1.9 \mathrm{GPa}$, respectively) and good tensile strength (50 and $29 \mathrm{MPa}$, respectively).[19] However, their elongation at failure are weak (3.3 and 5\%, respectively), often requiring plasticization.[20] Several plasticizers have been screened as ester citrates,[21-23] lactide monomer or oligomers,[24-25] polyethylene glycol [26] or polypropylene glycol.[27]

In general context of endoprostheses, we selected rod morphology as model. The influence of plasticization on the hydrolytic degradation of PLGA rods was briefly investigated in the first part of the present work. On the one hand, D,L-lactide (D,L-LA) was selected as plasticizer due to its lower reactivity than glycolide.[17] On the other hand, aspirin (o-acetylsalicylic acid) that exhibits anti-platelet property[28-29] was also evaluated as plasticizer. Indeed, its progressive release from PLGA materials may be advantageous in biodegradable coronary stents application to reduce the intra-stent thrombosis risk. In the second part of this work, the influence of the strain rate on the tensile properties of D,L-LA plasticized (or not) PLGA rods in the dry state was studied according to Weibull statistical distribution.[30] Finally, tensile properties of such rods were also studied in the wet state, and water diffusion coefficients were estimated.

\section{Experimental Section}

\subsection{Materials}

PLGA (poly(D,L-lactide-co-glycolide), Purasorb® PDLG 5010) was purchased from Purac (former name of Corbion). The molar ratio of D,L-lactide and glycolide monomer units was 
$47 / 53$, according to our own analysis, and the viscosity-average molecular weight $\left(\overline{M_{v}}\right)$ was estimated to be $113.500 \mathrm{~g} / \mathrm{mol}$. D,L-lactide (D,L-LA; Alfa Aesar) was recrystallized twice from toluene and dried under vacuum. Aspirin was purchased from Aldrich and used as received. 1,1,1,3,3,3-hexafluoropropan-2-ol (HFIP; Apollo Scientific) was used as received.

\subsection{Preparation of PLGA rods}

PLGA and plasticizers (D,L-LA and aspirin) were dried under vacuum at $35^{\circ} \mathrm{C}$ over one night, then blended. Extruded rods were obtained using a single screw extruder at $150^{\circ} \mathrm{C}$, with speed of $15 \mathrm{rpm}$. Rods with $1 \mathrm{~mm}$ diameter were obtained for commercial PLGA, when 0.5 $\mathrm{mm}$ average diameter rods were produced for plasticized PLGA due to the decrease of the polymer viscosity. Rods were cut into $30 \mathrm{~mm}$ length for further studies.

PLGA was characterized before and after extrusion, with or without plasticizers (Table 1). Initial $\overline{\mathrm{M}_{\mathrm{v}}}$ of commercial PLGA dropped to $70.000 \mathrm{~g} / \mathrm{mol}$ after extrusion, whatever the presence of plasticizer. This PLGA degradation is due to the extrusion process as already reported.[31-32] The glass transition temperature (Tg) of commercial PLGA powder is around $45^{\circ} \mathrm{C}$, when PLGA rods containing $5 \%$ wt. of D,L-lactide or $2 \%$ wt. of aspirin (confirmed using a calibration curve Tg $v s . \%$ wt. of plasticizer) exhibit Tg equal to $39^{\circ} \mathrm{C}$ and $36^{\circ} \mathrm{C}$, respectively (Table 1 ).

\subsection{Characterization techniques}

Viscometric measurements of PLGA solutions in HFIP were carried-out using an Ostwaldtype capillary viscometer $(0.46 \mathrm{~mm}$ diameter $)$. Temperature $\left(30^{\circ} \mathrm{C}\right)$ was regulated by a circulating bath. $\overline{\mathrm{M}_{\mathrm{v}}}$ were estimated according Mark-Houwink relationship where $\mathrm{K}=1.6410^{-4}$ and $\mathrm{a}=0.794 .[33] \mathrm{Tg}$ were determined using DSC 131 (Setaram) under helium flow. The samples were firstly heated to erase any anterior thermal history, then heated from -50 to $70^{\circ} \mathrm{C}$ with a ramp of $10^{\circ} \mathrm{C} / \mathrm{min}$. The tensile tests were performed on a Zwicki-Line $\mathrm{Z} 2.5$ 
(Zwick Roell), at strain rates between 0.1 to $500 \mathrm{~mm} \cdot \mathrm{min}^{-1}$. Each test was repeated at least 5 times. Optical microscopy analyses were performed using Leica MZ 12 fit out with Hitachi monochromatic camera for frame capture. Scanning electron microscope (SEM) Quanta 600 FEG (FEI) was used in large field detector mode, acceleration voltage of $2.5-3.5 \mathrm{kV}$, pressure of 70-130 Pa, focusing of 3-6 mm and 200-6000 in magnification.

\subsection{In vitro hydrolytic degradation}

Rods were suspended into $10 \mathrm{~mL}$ of $0.13 \mathrm{M}$ isomolar phosphate buffer (PBS) solution (pH 7.4) containing $0.02 \%$ of $\mathrm{NaN}_{3}$ to prevent bacteria development. The flasks were kept stirring in an oven at $37^{\circ} \mathrm{C}$ and $60 \mathrm{rpm}$. Samples were withdrawn from the ageing media every week, washed with distilled water and dried under vacuum. After drying, the samples were weighed and the weight loss (WL) was determined according eq. 1 , where $\mathrm{W}_{0}$ and $\mathrm{W}_{1}$ are the initial and remaining weights of the samples, respectively.

$$
W L(\%)=\frac{W_{0}-W_{1}}{W_{0}} \times 100
$$

Supposing that the hydrolytic degradation leads to the same amount of L- and D-lactic acids, the L-lactic acid release was monitored by enzymatic reaction. Hundred microliters of ageing media were added to $1 \mathrm{~mL}$ of glycylglycine buffer containing $0.2 \mathrm{~mL}$ of NAD (nicotinamideadenine dinucleotide), $0.02 \mathrm{~mL}$ of GPT (glutamate pyruvate transaminase) and $0.9 \mathrm{~mL}$ of ultrapure water. After $5 \mathrm{~min}$, the absorbance $\left(\mathrm{A}_{1}\right)$ of these solutions was measured by UV/visible spectrometry at $340 \mathrm{~nm}$. Then, twenty microliters of L-LDH (L-lactate dehydrogenase) were added. After $30 \mathrm{~min}$ of reaction time, second absorbance measurements $\left(A_{2}\right)$ were performed. Before testing the ageing media, the same measurements were made with water to determine the $\mathrm{A}_{1}$ and $\mathrm{A}_{2}$ blank values. $\Delta \mathrm{A}$ was estimated according to eq 2 , then the released L-lactic acid amount was estimated using one calibration curve $(\Delta \mathrm{A} v s$. L-lactic acid concentration). 
$\Delta \mathrm{A}=\left(\mathrm{A}_{2}-\mathrm{A}_{1}\right)_{\text {sample }}-\left(\mathrm{A}_{2}-\mathrm{A}_{1}\right)_{\text {blank }}$

\subsection{Weibull method}

Description of the two-parameter Weibull method is given by eq. 3, where $P_{R}$ is the cumulative probability of failure of a rod of volume $\mathrm{V}$ at applied uniaxial tensile stress $\sigma$. The term $\sigma_{0}$ represents the characteristic tensile strength where $63 \%$ of samples break (also called Weibull normal factor). $\mathrm{m}$ is the reliability parameter called Weibull modulus.

$\mathrm{P}_{\mathrm{R}}=1-\exp \left(-V\left(\frac{\sigma}{\sigma_{0}}\right)^{m}\right)$

The cumulative failure probability $\left(\mathrm{P}_{\mathrm{R}}\right)$ under a particular stress is estimated experimentally using eq. 4 , where $\mathrm{i}$ is the rank order of the tensile strength at break and $\mathrm{N}$ is the total number of tested rods.

$$
P_{R} \approx \frac{i}{N+1}
$$

Linearization of eq. 3 gives eq. 5 that allows the evaluation of the Weibull distribution parameters $\left(\mathrm{m}\right.$ and $\left.\sigma_{0}\right)$.

$\ln \left(\ln \frac{1}{1-\mathrm{P}_{\mathrm{R}}}\right)=\mathrm{m} \ln \sigma-\mathrm{m} \ln \sigma_{0}$

The Weibull's modulus $(\mathrm{m})$ is characteristic of the dispersion of internal defects of the sample. When $m<20$, this defects distribution is widely dispersed. Consequently, in these cases, $\sigma_{0}$ has to be considered as another important parameter to take account. When $\mathrm{m}>20$, the defects distribution is less dispersed and the mechanical strength can be unequivocally evaluated.

\subsection{Water diffusion model}

After water diffusion, the yield stress $\left(\sigma_{\mathrm{e}}\right)$ of PLGA rods can be estimated according to a mixing law: 
$\sigma_{e}=f_{c} \sigma_{e}^{c}+\left(1-f_{c}\right) \sigma_{e}^{s}$

where $f_{c}$ and $\sigma_{e}^{c}$ are the fraction and the yield stress of the inner pure PLGA core, respectively. $\sigma_{\mathrm{e}}^{\mathrm{s}}$ is the yield stress of the water-plasticized PLGA shell (Figure 1).

If one makes the assumption that the core exhibits a higher yield strength than the shell, the mechanical strength of rod is directly related to the effective pure PLGA section area, ie. $\pi(\mathrm{R}-\mathrm{e})^{2}$. Consequently

$$
\sigma_{\mathrm{e}}^{\mathrm{s}}<<\sigma_{\mathrm{e}}^{\mathrm{c}}
$$

(6) and (7) give

$$
\sigma_{\mathrm{e}}=\mathrm{f}_{\mathrm{c}} \sigma_{\mathrm{e}}^{\mathrm{c}}
$$

As $e \ll R$, $\mathrm{f}_{\mathrm{c}}$ can be estimated by

$$
f_{c}=1-\frac{2 e}{R}
$$

From (8) and (9), one finds

$$
\sigma_{e}=\left(1-\frac{2 e}{R}\right) \sigma_{e}^{c}
$$

The decrease of the tensile strength at yield $\left(\Delta \sigma_{e}\right)$ due to the water-plasticized shell (thickness =e) can be expressed according to

$$
\Delta \sigma_{e}=\sigma_{e}-\sigma_{e}^{c}=-\frac{2 e}{R} \sigma_{e}^{c}
$$

So

$$
\frac{\Delta \sigma_{\mathrm{e}}}{\sigma_{\mathrm{e}}^{\mathrm{C}}}=-\frac{2 \mathrm{e}}{\mathrm{R}}
$$

On another hand, Fick's law gives

$$
\langle e\rangle \approx \sqrt{D t}
$$


where $\langle\mathrm{e}\rangle$ is the mean path of the water flow at time t, D is the coefficient of diffusion of water in the polymer.

From relations (10) and (13), one can express the evolution of the apparent yield stress of the polymer as a function of time

$$
\sigma_{\mathrm{e}} \approx\left(1-\frac{2 \sqrt{\mathrm{Dt}}}{\mathrm{R}}\right) \sigma_{\mathrm{e}}^{\mathrm{c}}
$$

This Fickian model assumes an homogenous water diffusion into PLGA rods but a heterogeneous degradation of such rods occurs, as it will be shown below. Consequently, this simple Fickian model allows a rough estimation of the water diffusion coefficient.

\section{Results and Discussion}

After extrusion, plasticized (or not) PLGA rods were characterized by DSC to both evaluate Tg and actual plasticizer amount (Table 1). D,L-lactide is less reactive that glycolide and we already observed that $99 \%(100 \%)$ of glycolide has disappeared after 20 min (1 hour) of SnOct $_{2}$-catalyzed ROP, while only 75\% (95\%) of D,L-lactide has reacted.[17] Consequently $5 \%$ of D,L-lactide was considered as the possible residual monomer amount in crude PLGA, before industrial extrusion. A lower amount of aspirin (2\% wt. ) was selected to obtain enough fast degradation as it will be shown below. Moreover, we observed aspirin/PLGA or D,L-lactide/PLGA homogenous blends.

\subsection{Degradation study}

The hydrolytic degradation of PLGA rods (plasticized by D,L-LA, by aspirin or not plasticized) has been studied in PBS medium at $37^{\circ} \mathrm{C}$. The degradation was monitored by the weight loss and the lactic acid release in the aqueous medium (Figure 2). For all the samples, the degradation starts quickly, after 1 or 2 weeks of immersion in PBS. The degradation velocity is very fast and the weight loss values are close to $100 \%$ after 9 to 10 weeks. The half-time degradation $\left(t_{1 / 2}\right)$ of such rods varies according to their chemical nature, but is still 
lower than one month. As shown in Figure 2 and according the hydrophilic and acidic characters of the plasticizers we used, plasticized rods degrade faster than not plasticized rods. More precisely, aspirin plasticized rods degrade faster than D,L-lactide plasticized rods, while a lower aspirin content was used ( $2 \% \mathrm{wt}$ of aspirin vs $5 \% \mathrm{wt}$ of D,L-lactide). That is due to the acidity of such plasticizers ( $\mathrm{pKa}=3.49$ for aspirin vs $\mathrm{pKa}=3.86$ for $\mathrm{D}$, L-lactic acid that is produced after hydrolysis of D,L-lactide). The profile of L-lactic acid release curve is in agreement with the weight loss one. Nevertheless, L-lactic acid release starts after the weight loss, because of the production of hydrosoluble oligomers remaining inside the rods.[34] Indeed, even such oligomers can diffuse outside, the specific enzyme used for the L-lactic acid measurement cannot detected them.

The sigmoid curves (Figure 2) are typical of heterogenous degradation.[35] After 1-2 weeks immersion in PBS and depending the chemistry of the rod, optical micrographs (Figure 3) point out rods were composed of chambers containing liquid by-products produced during degradation. Then, hollow rod was observed after 24 days in PBS (Figure 3A). In case of plasticized rods (Figure 3B and 3C), very brittle rods were clearly observed. Such microscopy observations distinctly highlight formation of hollow structures according heterogeneous degradation as already observed.[35] Indeed, water penetrates into PLGA materials core and the ester links start to hydrolyse.[34] On the one hand, each scission leads to the production of carboxylic acid at PLGA chain ends. Such carboxylic acid catalyzes the ester hydrolysis, leading to accelerate the molecular weight reduction. As soon as formed oligomers present sufficiently low molecular weight to become soluble in aqueous phase, they diffuse outside the rods to produce hollow materials. On the other hand, materials surface cannot undergo such autocatalytic degradation.[34] Firstly, the PBS aqueous medium neutralizes carboxylic acids. Secondly, the hydrosoluble oligomers produced at the surface can easier diffuse outside the materials. Consequently, in case of studied rods, the degradation is faster inside and leads to an hydrolytic differentiation between the core and the shell. Finally, hollow rods are 
formed (Figure 3), as already reported in case of PLGA with lactide/glycolide molar ratio equal to $75 / 25 .[36,37]$

\subsection{Tensile properties in the dry state}

To mimic potential temporary endoprostheses applications, we chose to study the tensile properties of such plasticized (or not) PLGA rods. Indeed, such deformation velocities may be experienced during the deployment/positioning of coronary stents. Unfortunately, and oppositely to D,L-LA plasticized PLGA rods, extruded rods containing aspirin were not well geometrically defined due to a certain diameter variability. Consequently, the mechanical properties of these last rods were not determined.

The tensile tests were realized with strain rates of $0.1,1,10,100$ and $500 \mathrm{~mm} \cdot \mathrm{min}^{-1}$ in order to study the impact of strain rate on the tensile stress value. Although typical stress/strain curves of viscoplastic polymer was observed (Figure 4), first tensile tests revealed dispersion of the properties for a given strain rate (Figure 5). To overcome this limitation, we choose to apply Weibull method[30] as already reported for some polymeric materials.[34-35] That is a wellestablished characterization tool in the field of brittle materials, where failure may occur by crack growth from a single defect. The results obtained for D,L-lactide plasticized (or not) PLGA rods are exposed in table 2, according to Weibull distribution. On the one hand, a significant increase of the strength at failure probability of $63 \%\left(\sigma_{0}\right.$, Weibull normal factor $)$ with strain rate was observed, according to the viscoplastic behavior of plasticized (or not) PLGA. Moreover, for a given strain rate, $\sigma_{0}$ decreases after D,L-lactide plasticization according the decrease of the macromolecular chains cohesion by a small molecule like D,Llactide.[40] On the other hand, the plasticizer does not enhance the elongation at break as expected, certainly due to the low quantities of plasticizer used ( $<5 \%$ wt.). We can also observe that Weibull modulus (m) values are higher than 20 using higher strain rate. As rods arose from the same extrusion, defaults dispersion has to be roughly identical and (m) should 
not vary. This tendency is probably due to some influence of the strain rate on the breaking modes. Finally, by the determination of the characteristic strength at failure probability of $63 \%\left(\sigma_{0}\right)$, the Weibull distribution gives information about the ultimate conditions of use of such PLGA materials. As an example, these $\sigma_{0}$ values for plasticized (or not) PLGA are in agreement with biodegradable coronary stents application as the arterial wall exhibits breaking strength of 0.5 to $1.72 \mathrm{MPa}$ and a Young's modulus of the order of $1 \mathrm{MPa}$.[41] Furthermore, SEM analysis of the plasticized (or not) PLGA rods surface are performed to better understand the influence of the strain rate on the breaking mode. This reveals the presence of perpendicular crazes to the tensile axis, after tensile load. Before tensile test, no craze was observable by SEM analysis. Two different types of crazes can be distinguished (Figure 6) and can act as defects, which has favoured the crack growth in PLGA brittle rods. At high strain rate $\left(100 \mathrm{~mm} \cdot \mathrm{min}^{-1}\right)$, crazes appear at $2 \%$ of elongation, whatever the plasticization. The distance between primary crazes is approximately $40-60 \mu \mathrm{m}$, whatever the plasticization, while that between the secondary crazes is about $10 \mu \mathrm{m}$ for PLGA (about 20 $\mu \mathrm{m}$ in case of plasticized PLGA), and both are not evolving with the elongation studied (< $10 \%)$ (Figure 7). However, at low strain rate $\left(0.1 \mathrm{~mm} \cdot \mathrm{min}^{-1}\right)$, crazes appears at $5 \%$ of elongation whatever the plasticization, but are much more spaced and their dispersion is higher than at $100 \mathrm{~mm} \cdot \mathrm{min}^{-1}$ strain rate. These observations agree with the variation of $(\mathrm{m})$ parameter with strain rates (Table 2). Consequently, the presence and growth of the crazes do not seem to be governed by a strain threshold, but rather by a threshold stress. Indeed, for each applied strain rate, primary and secondary crazes become visible for an imposed stress amplitude of about $25 \mathrm{MPa}$, which seems to be the triggering threshold of their developing.

\subsection{Tensile properties in the wet state}

PLGA rods (D,L-lactide plasticized or not) were also studied after immersion in aqueous phosphate buffer (PBS, $\mathrm{pH} \mathrm{7.4)}$ at $37^{\circ} \mathrm{C}$, under $60 \mathrm{rpm} / \mathrm{min}$, to mimic the hydration that 
occurs under physiological conditions. This wet state tensile properties study was firstly realized at $100 \mathrm{~mm} \cdot \mathrm{min}^{-1}$ after various times of immersion (lower or equal to 1 week). In this case, the Weibull method was not applied because the tensile tests didn't reveal dispersion after 1 day immersion. The results of tensile tests were reported on figure $\mathbf{8}$.

The yield stress $\left(\sigma_{\mathrm{e}}\right)$ of PLGA decreases with time of immersion, from $70 \mathrm{MPa}$ to $32 \mathrm{MPa}$ after one week immersion in PBS medium at $37^{\circ} \mathrm{C}$. That is due to the water diffusion into the rod, producing a water-plasticized PLGA shell and an inner core of pure PLGA (Figure 1). The same trend is observed in case of D,L-LA plasticized PLGA, where the yield stress decreases sharply with a final value of $10 \mathrm{MPa}$ after 4 days in PBS. This stronger drop is due to the higher hydrophilicity of D,L-LA plasticized PLGA, which accelerates faster absorption of water. This immersion in PBS also influences the values of the strain to failure $\left(\varepsilon_{\text {break }}\right.$, Figure 8B). In case of D,L-LA plasticized PLGA, $\varepsilon_{\text {break }}$ firstly increases during immersion due to the plasticization effect of the water, which enhances the rubbery behavior of PLGA. Finally, for both PLGA rods, $\varepsilon_{\text {break }}$ reaches a maximum before decreasing. This decrease may be due to the start of hydrolytic degradation as shown by optical microscopy observation revealing rods surface modification (Figure 9). Indeed, when the rods are immersed in aqueous medium, two phenomena influence the polymer tensile properties. In the initial stage of immersion, water molecules diffuse into PLGA to plasticize it. Then, after few days, the hydrolytic scission of the esters functions starts as above reported.

The strain rate also governs the tensile properties as usual (Figure 10). Again, SEM analysis of PLGA rods surface allows us to observe crazes after 7 days immersion in PBS. More surprisingly, primary and secondary crazes appear at $2 \%$ of elongation and do not depend both on the strain $(<8 \%)$ and on the strain rate $\left(0.1\right.$ and $\left.100 \mathrm{~mm} \cdot \mathrm{min}^{-1}\right)$. The distance between primary crazes was approximately $80 \mu \mathrm{m}$, while that between the secondary crazes was about $30 \mu \mathrm{m}$. These results highlight the strong influence of aqueous medium on the mechanical 
stress. Indeed, the water influence on tensile properties appears to be stronger than the effect of strain rate. After immersion in PBS, the tensile strength at yield $\left(\sigma_{\mathrm{e}}\right)$ of PLGA rods may be expressed using the approximate eq. 14. Experimental $\sigma_{\mathrm{e}}$ values (Figure 11) are in good agreement with our theoretical diffusion model issued from eq. 14, and one can estimate the water diffusion coefficients (D) in D,L-LA plasticized (or not) PLGA rods (Figure 11). The

values given in Figure 11 agree with the rare one from the literature (about $110^{-12} \mathrm{~m}^{2} \cdot \mathrm{s}^{-1}$ in case of poly(D,L-Lactide)).[42] As expected, the water diffusion coefficient is higher in case of plasticized PLGA, which is more hydrophilic and has lower glass transition temperature.

\section{Conclusions}

Firstly, we studied the hydrolytic degradation of such PLGA rods, plasticized or not with D,Llactide or aspirin. According literature, a heterogeneous degradation occurred in such rods that exhibit diameter larger than $0.5 \mathrm{~mm}$ after extrusion. Chambers of liquid oligomers have been observed after 1-2 weeks immersion in PBS, when hollow rods were obtained after 21 days. In addition and as expected, the addition of the chosen plasticizers, especially aspirin, accelerate the rods degradation.

Secondly and whatever the strain rate, tensile tests in the dry state on D,L-LA plasticized (or not) PLGA rods revealed dispersion that prevents the evaluation of tensile properties of such materials. Nevertheless, it has been overcome using Weibull method that allow us to estimate the characteristic strength probability of $63 \%\left(\sigma_{0}\right)$, depending on the strain rate. This method highlighted also the strain rate governs the breaking modes. Indeed, SEM analysis confirms the observation of crazes, that are correlated to a threshold stress of $25 \mathrm{MPa}$ and that catalyzed crack growth of such PLGA brittle rods.

Finally, tensile tests in the wet state didn't show such dispersion in results. The water plasticization of rods has been highlighted by the decrease of the yield stress $\left(\sigma_{\mathrm{e}}\right)$ and with the 
increase of break elongation $\left(\varepsilon_{\text {break }}\right)$. Using an adequate model, the diffusion coefficients of water in such rods has been estimated and agree with the rare value reported in literature.

Biodegradable stents with low half-life time have been selected in this paper to illustrated one very interesting application. Hydrolytic degradation study proved that a half-life time lower than one month can be expected for such stents. We also showed that tensile properties of such PLGA rods matched with those of arterial wall. Nevertheless, the design of such rods are too straightforward and has to be optimized in the future to perfectly match with specification of such application. Moreover, release of aspirin from such PLGA rods will also be investigated in the next future.

\section{Acknowledgements:}

The authors express their highest gratitude to i) Dr. Marc Ponçot (Institut Jean Lamour UMR 7198, France) for help in SEM analysis; ii) Laboratoire Réactions et Génie des Procédés (UMR 7274, France) for Optical microscopy analysis and to iii) MS-Techniques (Pompey, France) for extrusion. 


\section{References:}

[1] Vink E.T.H., Rabag K.R., Glassner D.A., Gruber P.R., Polymer Degradation and Stability, 80, 403-419 (2003)

[2] Shen L., Worrell E., Patel M., Biofuels, Bioproducts and Biorefining, 4, 25-40 (2010)

[3] Singhvi M., Gokhale D., RSC Advances, 3, 13558-13568 (2013)

[4] Ikada Y., Tsuji H., Macromolecular Rapid Communications, 21, 117-132 (2000)

[5] Pillai C. K. S., Sharma C. P., Journal of Biomaterials Applications, 25, 291-366 (2010)

[6] Waris E., Konttinen Y. T., Ashammakhi N., Suuronen R., Santavirta S., Expert Review of Medical Devices, 1, 229-240 (2004)

[7] Middleton J. C., Tipton A. J., Biomaterials 21, 2335-2346 (2000)

[8] Lafont A., Li S.M., Garreau H., Cornhill F., Vert M., Journal of Biomedical Materials Research Part B: Applied Biomaterials, 77B, 349 - 356 (2006)

[9] Wang X., Venkatraman S.S., Boey F.Y.C., Loo J.S.C., Poh Tan L., Biomaterials, 27, $5588-5595$ (2006)

[10] Platel R. H., Hodgson L. M., Williams C. K., Polymer Reviews, 48, 11-63 (2008)

[11] Madhavan Nampoothiri K., Nair N. R., John R. P., Bioresource Technology 101, 8493-8501 (2010)

[12] Kamber N. E., Jeong W., Waymouth R. M., Pratt R. C., Lohmeijer B. G. G., Hedrick J. L., Chemical Reviews, 107, 5813-5840 (2007)

[13] Ottou W.N., Sardon H., Mecerreyes D., Vignolle J., Taton D., Progress in Polymer Science, 56, 64-115 (2016)

[14] Guerin W., Helou M., Carpentier J.F., Slawinski M., Brusson J.M., Guillaume S.M., Polymer Chemistry 4, 1095-1106 (2013)

[15] Fernandez J., Meaurio E., Chaos A., Etxeberria A., Alonso-Varona A., Sarasua J. R., Polymer 54, 2621-2631 (2013) 
[16] Kricheldorf H. R., Rost S., Biomacromolecules, 6, 1345-1352 (2005)

[17] Duval C., Nouvel C., Six J.L., Journal of Polymer Science Part A: Polymer Chemistry, 52, 1130-1138 (2014)

[18] Alexis F., Polymer International 54, 36-46 (2005)

[19] Anderson K. S., Schreck K. M., Hillmyer M. A., Polymer Reviews, 48, 85-108. (2008)

[20] Engleberg I., Kohn J., Biomaterials, 12, 292-304 (1991)

[21] Labrecque L. V., Kumar R. A., Davé V., Gross R. A., McCarthy S. P., Journal of Applied Polymer Science, 66, 1507-1513 (1997)

[22] Ljundberg N., Andersson T., Wesslén B., Journal of Applied Polymer Science, 88, $3239-3247$ (2003)

[23] Ljundberg N., Wesslén B., Polymer, 44, 7679-7688 (2003)

[24] Sinclair R. G., Journal of Macromolecular Science, Part A: Pure and Applied Chemistry, 33, 585-597 (1996)

[25] Martin O., Avérous L., Polymer, 42, 6209-6219 (2001)

[26] Baiardo M., Frisoni G., Scandola M., Rimelen M., Lips D., Ruffieux K., Wintermantel E., Journal of Applied Polymer Science, 90, 1731-1738 (2003)

[27] Kulinski Z., Piorkowska E., Gadzinowska K., Stasiak M., Biomacromolecules, 7, $2128-2135$ (2006)

[28] Catella-Lawson F., Reilly M.P., Kapoor S.C., Cucchiara A.J., De Marco S., Tournier B., Vyas S.N., FitzGerald G.A., The New England Journal of Medicine, 345, 1809-1817 (2001)

[29] Patrono C., The New England Journal of Medicine, 330, 1287-1294 (1994)

[30] Weibull W., Journal of Applied Mechanics, Transactions ASME, 18, 293-297 (1951)

[31] Taubner V., Shishoo R., Journal of Applied Polymer Science, 79, 2128-2135 (2001)

[32] F., Pages P., Gamez-Perez J., Santana O.O., Maspoch M.L., Polymer Degradation and Stability, 95, 2508-2514 (2010) 
[33] Kenley R. A., Lee M. O., Randolph Mahoney T., Sanders L. M., Macromolecules, 20, 2398-2403. (1987)

[34] Li S., Garreau H., Vert M., Journal of Materials Science: Materials in Medicine, 1, $198-206(1990)$

[35] Grizzi I., Garreau H., Li S., Vert M., Biomaterials, 16, 305-311 (1995)

[36] Li S., Garreau H., Vert M., Journal of Materials Science: Materials in Medicine, 1, $131-139(1990)$

[37] Li S., Vert M., Macromolecules, 27, 3107-3110 (1994)

[38] Naito K., Journal of Applied Polymer Science, 128, 1185-1192 (2013)

[39] Ben Jar P.Y., Xu J., Polymer Engineering \& Science, 51, 573-584 (2011)

[40] Murariu M., Da Silva Ferreira A., Alexandre M., Dubois P., Polymers for Advanced Technologies, 19, 636-646 (2008)

[41] Silver F. H., In Biomaterials, Medical Devices \& Tissue Engineering: an integrated approach; F. H. Silver Ed.; Springer: New York, Chapter 1, pp 1-45 (1994)

[42] Davis E. M., Theryo G., Hillmyer M. A., Cairncross R. A., Elabd Y. A., ACS Applied Materials \& Interfaces, 3, 3997-4006 (2011) 